\title{
The Djibouti francolin and juniper forest in Djibouti: the need for both ecosystem and species-specific conservation
}

\author{
Zomo S. Y. Fisher, Samantha Cartinight, Clive Bealey \\ Houssein A. Rayaleh, Philip McGowan and E. J. Milner-Gulland
}

\begin{abstract}
The majority of Galliformes are ground dwelling, many live in forests, and c. $25 \%$ are on the IUCN Red List. The Djibouti francolin Francolinus ochropectus is a Critically Endangered galliform endemic to only two areas of relict Juniperus procera forest in Djibouti. This study assessed population status and habitat condition in the species' stronghold in the Forêt du Day during the postbreeding season. Line transect distance sampling was used to survey the francolin, recording visual encounters and calls. Canopy and understorey vegetation were sampled across the study area at $150-\mathrm{m}$ intervals using $400-\mathrm{m}^{2}$ quadrats. Interviews were conducted in all adjacent villages to obtain information about francolin sightings, forest use and capacity for community-based conservation. Distance was used to generate francolin population density estimates. A geographical information system and generalized linear modelling were used to determine predictors of francolin presence and juniper condition. The Distance model estimated francolin density to be $38-94 \mathrm{~km}^{-2}$. Within the Foret du Day this is equivalent to a population of 285-705 individuals. The presence of juveniles in the samples suggests that the effective population size may be lower and therefore, although this is the first estimate of Djibouti francolin density using standard survey methodology, it should be interpreted cautiously. Juniper condition in the Forêt du Day is poor. The healthiest forest is $50 \%$ dead. Francolins are more abundant where tree cover is high. This cover now mostly consists of Buxus hildebrandtii, which appears to have mostly replaced the original juniper. In areas of high tree cover, grazing intensity is significantly negatively correlated with francolin presence. Anthropogenic influences on juniper health and
\end{abstract}

Zomo S. Y. FisheR* (Corresponding author) Centre for Environmental Policy, Imperial College London, London, UK. E-mail zomo.fisher@erm.com

Samantha Cartwright Centre for Agri-Environmental Research, School of Agriculture, Policy and Development, University of Reading, UK.

Clive Bealey and Philip McGowan World Pheasant Association, Newcastle, UK.

Houssein A. Rayaleh Djibouti Nature, Djibouti.

E. J. Milner-Gulland Conservation Science, Division of Biology, Imperial College London, London, UK.

${ }^{*}$ Present address: Environmental Resources Management, Exchequer Court, 33 St Mary Axe, London, EC3A 8AA, UK.

Received 18 September 2008. Revision requested 23 December 2008.

Accepted 23 February 2009. francolin decline are mediated through the large number of cows grazing in the forest. We recommend an ecosystem approach to conservation of the forest, with additional species-specific protection measures for the francolin and juniper.

Keywords Climate, distance sampling, Djibouti, ecosystem, Francolinus ochropectus, Juniperus procera, overgrazing, presence/absence modelling

\section{Introduction}

The vast majority of Galliformes are ground dwelling, 1 many live in forests (Fuller et al., 2000) and c. $25 \%$ are on the IUCN Red List (IUCN, 2008). Galliformes face persecution from hunting because of the high protein content of their meat and eggs and their ease of capture (Fuller et al., 2000). Most declines of Galliformes are, however, attributed to habitat destruction caused by deforestation (del Hoyo et al., 1994; BirdLife, 2008), forest clearance for agriculture (Javed et al., 1999) and urban development (Dai et al., 1998). Forest fragmentation in particular can isolate populations of terrestrial birds unable to fly long distances between fragments (Laurance et al., 1998; Sekercioglu, 2007). Such small isolated populations can suffer from inbreeding depression and genetic drift and are less resistant to shocks such as drought (Laurance \& Williamson, 2001; Keller \& Waller, 2002; Stephens et al., 2004). Intensive pastoralism is a contributing factor to the decline of Galliformes such as Nahan's francolin Francolinus nahani, a strict tropical rainforest specialist in the highly degraded Mabira forest in eastern Uganda and the Democratic Republic of Congo (Dranzoa, 1998; Fuller et al., 2000). Other species, however, are regularly found in secondary and degraded habitats (e.g. the orange-necked hill-partridge Arborophila davidi in southern Vietnam) and are able to tolerate appreciable amounts of disturbance (Atkins \& Tentij, 1999; Fuller et al., 2000; Lawes et al., 2006). Generalist species tend to have better tolerance of habitat loss and degradation, whereas long generation time and large body size, in particular, put birds at risk of persecution (Owens \& Bennett, 2000). Generalist species living in diverse habitats are at a significantly lower risk than more specialized species (Sekercioglu et al., 2004; Keane, 2005). Forest degradation 
and fragmentation are thus a cause of concern for many forest specialists. The Djibouti francolin Francolinus ochropectus, one of 41 species in the genus Francolinus, is believed to be a specialist, occurring only in a restricted area in the mountains of Djibouti (Fuller et al., 2000).

The Djibouti francolin is believed to have suffered a rapid population decline that is likely to continue unless there is concerted conservation action (Fuller et al., 2000; IUCN, 2008). The species' total range is probably no more than $35 \mathrm{~km}^{2}$ (McGowan et al., 1995) and the only viable population may be in the Goda Massif of Djibouti. However, the estimated $14-15 \mathrm{~km}^{2}$ of suitable habitat there has deteriorated markedly, having halved over 1977-1983 (Crowe et al., 1986). The Djibouti francolin also occurs in the adjacent Mabla Mountains c. $80 \mathrm{~km}$ to the north-east.

In 1985 the total population of the Djibouti francolin was probably $>5,000$ individuals (Blot, 1985) but by 1995 it was believed to number <1,000 (McGowan et al., 1995). In 1998 the population in the Forêt du Day in the Goda Massif was estimated to be c. 500-1,000 (Fuller et al., 2000). The status of the reported population in the Mabla Mountains is unknown. The francolin inhabits juniper Juniperus procera forest on the plateau of the Goda Massif and on the wooded slopes in the wadis that descend from it. The loss and deterioration of the juniper forest is a cause for concern as this habitat would have originally occupied a substantial portion of the francolin's range in the Goda Massif. In 1998 it was reported that the condition of the juniper was deteriorating (Magin, 2001) but the reasons, and any potential impacts on the francolin, were unclear.

$J$. procera is the only juniper species in sub-Saharan Africa and is predominantly distributed in the mountainous regions and highlands of East Africa and the uplands adjoining the Red Sea in Saudi Arabia and Yemen. The altitudinal range of the juniper forest in Djibouti is $1,300-$ $1,783 \mathrm{~m}$ and the juniper forest of the Forêt du Day is the last remnant of this previously much more extensive mixed woodland (White, 1983; Blot, 1986). Its deterioration exemplifies what has happened to montane juniper forest ecosystems elsewhere in the Arabian Peninsula (Asmodé, 1989; Blot \& Hajar, 1994; Gardner \& Fisher, 1994; Fisher, 1997), south-west Asia (Ahmed et al., 1990) and parts of Africa (Miskell, 2000; Borghesio et al., 2004) as a result of climatic changes, livestock grazing, acid rain, commercial wood extraction and agricultural encroachment. Montane juniper ecosystems in these regions are thus often isolated, high-altitude relict patches of forest. In Djibouti the juniper forest is heavily used by sedentary pastoral communities for livestock grazing, fuelwood, timber and minor commercial forest products such as honey (Emerton, 1999). The decline of the juniper forest has been attributed to extended dry seasons, acid rain and fungal infection (Gouvernement de Djibouti, 2000).

A preliminary survey was carried out in the Goda Massif in February-March 2004 using a 40-km-long transect, covering an area of c. $70 \mathrm{~km}^{2}$, to examine the density and extent of the francolin population and map and assess habitat condition. The total number of adult francolins recorded was 105-124, giving a minimum of 8.75-10.33 adults km $\mathrm{km}^{-2}$ and a total estimate of 612-723 adults across the Goda Massif. A structured questionnaire survey was also undertaken with 171 interviewees in 20 villages in the Goda Massif. The full results of this survey (Bealey et al., 2006) are not presented here but informed a more detailed study, which is the focus of this paper.

As there was insufficient information available to guide the development of conservation measures for the Djibouti francolin and its juniper forest habitat we assessed: (1) the condition of the juniper in the Forêt du Day, (2) the distribution of the francolin, (3) whether there is a correlation between the condition of the forest and the distribution of the francolin, and (4) the nature of human influence in the area. We use these assessments to recommend conservation measures for the francolin and the Forêt du Day ecosystem.

\section{Study area}

The c. $7.5-\mathrm{km}^{2}$ Forêt du Day is a dry tropical Afromontane mixed woodland in the Goda Massif mountain range in the Republic of Djibouti (Fig. 1) at altitudes of 1,200-1,750 m and is an International Endemic Bird Area (Magin, 2001). The forest includes a large central plateau (Garab), the Barabarre mountains to the south and the smaller Adonta plateau to the north. In close proximity $\left(<_{3} \mathrm{~km}\right)$ to the forest's western and northern edges are seven villages, comprising a total of c. 250 households. The dominant tree was formerly the African pencil cedar J. procera, which formed a closed-canopy forest until a dramatic decline in the past 20-30 years left a large proportion of the junipers dead and dying and the canopy open (Blot, 1986, 1994; Bealey et al., 2006). The climate of the Forêt du Day is tropical submontane, with frequent rain in the wet season (October-May) and hot and humid with sporadic rainfall in the dry season (June-September; Gouvernement de Djibouti, 2000). Mist and fog often engulf the higher elevations. There have been frequent droughts since 1985 but rain returned to the area in 2006 after five seasons of consecutive drought (USAID, 2008).

\section{Methods}

The 2004 preliminary survey of the Goda Massif found that the stronghold of the francolin population is in the Forêt du Day. In May-June 2007 a detailed survey was therefore carried out in this area. Systematic grid sampling with $20 \times 20-\mathrm{m}$ quadrats was used to record tree and shrub species and thus construct a vegetation map. Quadrats were equidistant to allow accurate spatial interpolation of data points. Vegetation is patchy and a $20 \times 20-\mathrm{m}$ quadrat was 


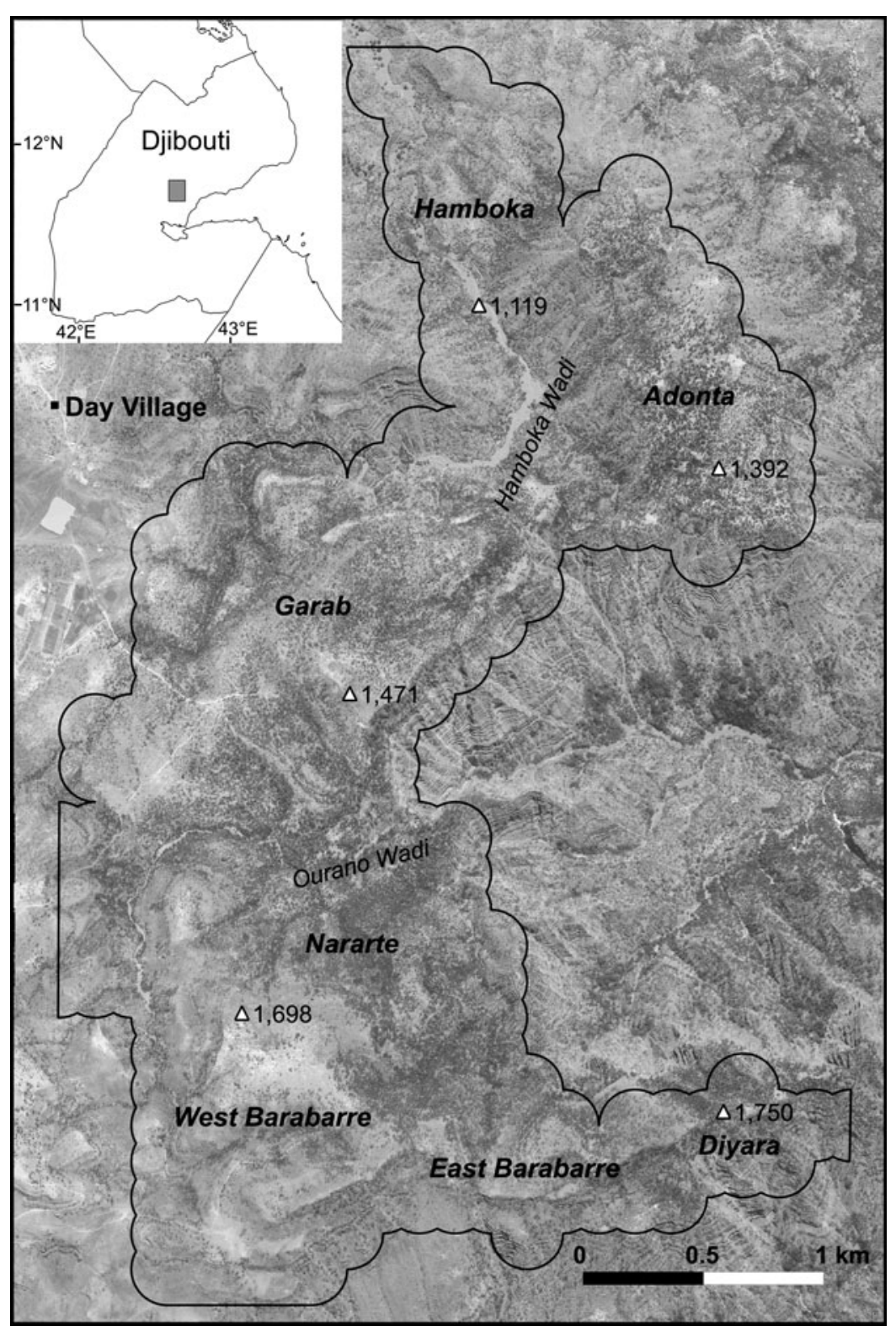

FIg. 1 The study area of the Forêt du Day on the Goda Massif, with places mentioned in the text and the boundary of the study area. The satellite photograph backdrop illustrates the landforms. The inset shows the location of the main map in Djibouti. the largest quadrat feasible that was representative of the plant species present whilst allowing a large number of quadrats to be surveyed within the time available. Quadrats were at $150-\mathrm{m}$ intervals, on a grid, corresponding to 44.4 quadrats $\mathrm{km}^{-2}$, with 330 quadrats in total.

A global positioning system (GPS) was used to navigate to each of the 330 predefined coordinates. In each quadrat the following data were collected: aspect, slope, altitude, grazing pressure (proxied by the number of piles of droppings from cows or other livestock, recorded on a scale of $0-4$ ), number of individuals of each species of tree and shrub (defined as a bush or large herbaceous plant $\geq 1 \mathrm{~m}$ in height), percentage crown cover for each tree species, condition of each juniper tree (estimated using a semiquantitative scale of $0-4$, later averaged for each quadrat, where o represented a dead tree without any living foliage (Plate 1a) and 4 represented a healthy tree with $100 \%$ foliage cover (Plate 1b); Fisher, 1997), and percentage cover of bare rock, bare soil, grasses and herb species. TWINSPAN (Hill \& Smilauer, 2005) was used to order the 330 quadrats, the results of which were interpreted by cross-referencing with a recent satellite image (6 May 2006) at a resolution of 2 feet (o.61 m) per pixel. A map of plant communities was drawn in ArcGIS v. 9.2 (ESRI, Redlands, USA). The density of dead and living junipers was calculated for each of the main habitats in the study area.

Francolins were surveyed at the same time each day (06.00-09.00, when they were most likely to be visible and calling; Welch \& Welch, 1985). Twenty-six systematically placed transects were surveyed (total length $17.1 \mathrm{~km}$ ). Some transects were difficult to navigate, and as a result, some start points could not be randomized. Other transects were placed parallel to each other, at 300-m intervals, based on the mean maximum francolin detection distance of $150 \mathrm{~m}$ 

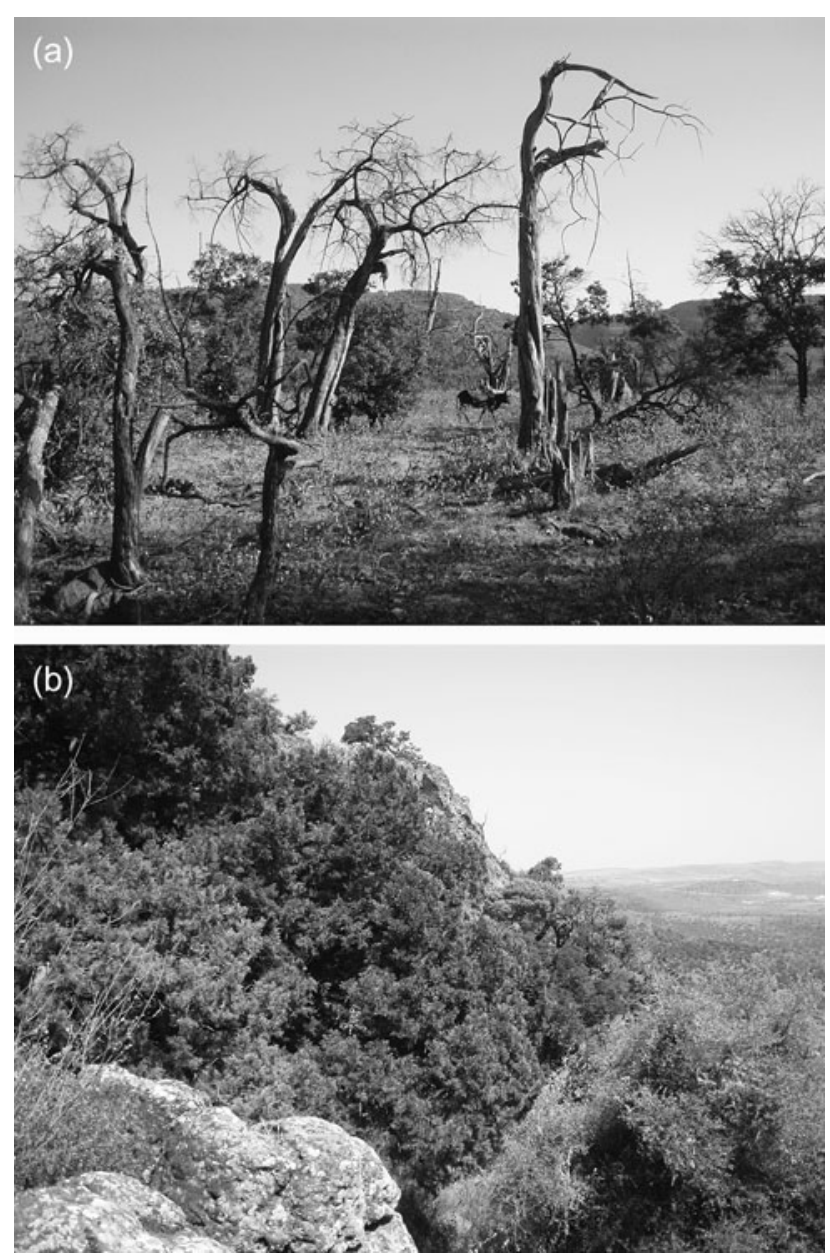

Plate 1 (a) Dead juniper (condition 0\%) on the Garab plateau and (b) healthy juniper (condition 100\%) at Diyara (Fig. 1).

calculated from the 2004 preliminary survey. Francolin observations were truncated $150 \mathrm{~m}$ either side of the transect. Transects were stratified according to terrain type. Lengths of transects were weighted proportionally between slopes and wadis ( $70 \%$ of the total area) and plateaus $(30 \%$ of the total area). Theoretically, $6.47 \mathrm{~km}^{2}$ was surveyed by the transects ( $86 \%$ of the study area) but, in reality, detection distances varied between areas of different topography. Upon encountering a bird sign (visual or audible) the observer's location was noted using a GPS. The estimated distance of the bird or cluster of birds from the observer, the bearing of the individual(s) from the observer and the cluster size were noted. These data were later used to calculate the birds' location.

To create a presence/absence data set for the francolin each transect was divided into 100-m sections in ArcGIS, each with a width of $300 \mathrm{~m}$ (based on 150-m truncation either side of the transect line), and thus each had an area of $30,000 \mathrm{~m}^{2}$. Sections of $100 \mathrm{~m}$ were chosen to produce a sufficient sample size for analysis and to minimize double counting and ensure independence of observations. ArcGIS was used to overlay bird locations on the sampling sections.
If a section contained one or more birds, it was given a value of 1 , and 0 if no birds were present. The environmental and biological variables from quadrat sampling were also overlaid using $\operatorname{ArcGIS}$ and continuous contour maps of each measured variable were created.

Generalized linear mixed modelling using the lme4 library in $R$ (Bates, 2007) was used to find the best biological and environmental predictors for bird presence. As the response variable is binomial, strictly bounded between $o$ and 1, with likely non-normal errors and nonconstant variance, the mixed model was run using the binomial family for data with binomial errors. The model with the lowest Akaike Information Criterion (AIC) was fitted with the logit link function using the Laplace method. A maximal model was initially fitted containing the main effects of altitude, grazing pressure, tree cover, mean juniper condition and plant community, and a random effect for transect number (to control for any possible bias in relation to the transect's location or other transectrelated effects). The models were run using different link functions of the binomial family and a minimum adequate model was chosen based on stepwise deletion of the model parameters that did not significantly explain any deviance in the model. Model selection followed the general rules provided by Crawley (2007).

Francolin density and cluster density were calculated using Distance v. 5.o (Thomas et al., 2006). All combinations of models and functions in Distance were fitted to the data and model selection was based on the model with the lowest AIC (Buckland et al., 2001). Cluster size was determined using the size bias regression method.

Interviews were conducted to explore differences in forest usage between villages and frequency of francolin sightings by region. The chief of the province of Day provided census information for each village. A stratified sample of $37.5 \%$ of the households was taken in the five villages that use the Forêt du Day: Day, Tikito, Goub, Oumdesaido and Hamboka. Households were selected systematically in each village. A total of 75 semi-structured interviews were conducted. Interviewees were typically the male owner of the household and were conducted by ZSYF in French. A French-Afar translator was required for some interviews. Questions were designed to be nonleading and sufficiently simple so as not to lose meaning in translation from French to Afar. The main questions in the interview aimed to determine: (1) the number of each type of animal owned and areas where they are grazed, observed recent trends in pasture quality, livestock productivity and change in numbers over time, (2) frequency of francolin sightings, areas where they were sighted and the importance of the francolin to villagers, and (3) perceived reasons for forest decline and ideas for forest management. To assess differences between villages general log-linear models were used (using the Poisson error family) to 
analyse complex contingency tables of count data (Crawley, 2007).

\section{Results}

\section{Status of the juniper forest}

Eight distinct plant communities were identified in the Forêt du Day by the TWINSPAN analysis. The eastern Barabarre plateau $(1,500-1,750 \mathrm{~m}$, with low grazing pressure) is dominated by dense living juniper and Olea europaea. Box Buxus hildebrandtii is mostly absent, whereas the western Barabarre plateau (with high grazing pressure at the same altitudinal range) is an arid open mixed woodland characterized by Tarchonanthus camphoratus, Euryops arabicus and dead juniper. Dense B. hildebrandtii woodland, mixed with juniper in some areas, dominates Barabarre mountain (1,450-1,600 m). The Garab plateau (c. 1,470 m, arid, with many clearings and uniformly high grazing) is open $B$. hildebrandtii woodland characterized by dead junipers; this region was once a closed-canopy juniper forest but it is now dominated by grazing-tolerant shrubs such as Nicandra physaloides and Withania somnifera. The Adonta region $(1,250-1,350 \mathrm{~m})$ is covered by a dense Buxus forest in the south and open Acacia seyal woodland in the north. It is drier because of its lower altitude but supports diverse vegetation on its hilly plateaus and varying topography types and has a dense herb cover throughout, with few living junipers. This area is closed to livestock by wood fences in all but 2 months of the year. The Hamboka region (1,00o$1,250 \mathrm{~m}$ ) is dominated by $A$. seyal. Juniper is absent. The cliff vegetation is diverse, benefiting from the Hamboka wadi, which is one of the largest in the province of Day and collects water from the Garab plateau. Grazing pressure generally decreases towards the east (away from the villages in the west) on Barabarre and Adonta.

Fig. 2 shows the density of living and dead junipers. The region with lowest tree condition and percentage of living

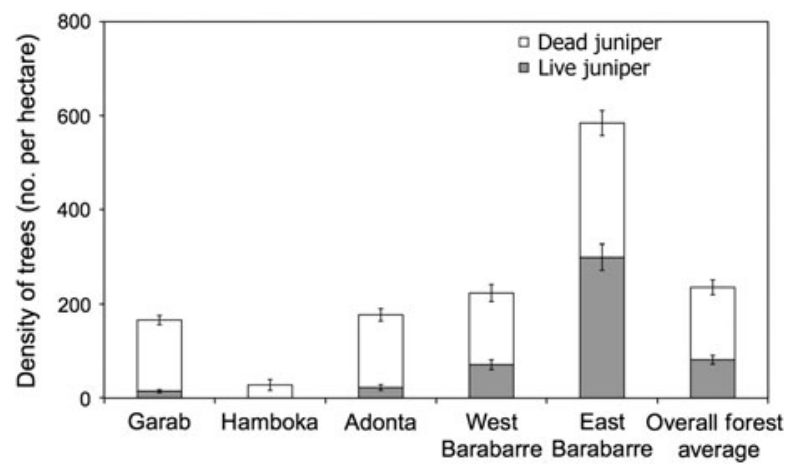

FIG. 2 Mean density (with standard error bars) of dead and living juniper Juniperus procera in the five main regions of the Forêt du Day (Fig. 1). juniper is Garab, where $<10 \%$ of junipers are living and, of these, the mean condition is $44.3 \%$. Hamboka has no living junipers. On Adonta only $12.7 \%$ of the juniper is living, with a mean condition of $57.5 \%$. In western Barabarre $31.8 \%$ of juniper are living, with a mean condition of $61.3 \%$. Eastern Barabarre has the highest density of both living and dead junipers; however, although $51.3 \%$ of the junipers are living, mean condition of these is only $60.6 \%$. All other regions have fewer junipers per ha and also have more dead than living juniper.

\section{Distribution and status of the Djibouti francolin}

The survey in the Forêt du Day comprised 47 observations of clusters of francolins, on the 26 transects, of which 26 were audible observations (with unknown cluster sizes) and 21 visual observations (cluster sizes of $1-5$ ). In visual and audible observations combined a minimum of 70 individuals were recorded. Francolins were not found uniformly throughout the Forêt du Day but rather in isolated patches. They were absent from most of the Garab plateau (apart from near the Ourano Wadi) and western Barabarre but found in Adonta, the north-facing slopes of Barabarre mountain (Nararte) and Diyara. Seventy percent of observations were in box-dominated areas.

The Distance model with the lowest AIC was halfnormal, fitted with a cosine function. Twelve equal intervals were chosen based on preliminary observation of the distribution of distances of observations from the centre line of the transects. The model fits the data closely in a goodness-of-fit test $\left(\chi^{2}=3.42, \mathrm{df}=3, \mathrm{P}=0.33\right)$. The model (Table 1) estimated a bird density of 60 francolins $\mathrm{km}^{-2}$ (95\% confidence interval $38-94 \mathrm{~km}^{-2}$ ). Extrapolating to the $7.5-\mathrm{km}^{2}$ study area, the estimated francolin population in the Forêt du Day is 450 (95\% confidence interval 285-705). The large confidence interval is a result of a high coefficient of variation (23\%).

Distance analysis gave mean and expected francolin cluster sizes of 1.74 and 2.06, respectively, with an estimated 29 clusters $\mathrm{km}^{-2}$. The larger expected cluster size suggests that some clusters were not observed or that some individuals remained out of sight and did not call and thus were not recorded, thus underestimating group size.

\section{Factors explaining francolin presence}

Francolin presence was not significantly associated with the main effects of plant community, altitude, grazing or transect. The minimum adequate model for francolin presence (Table 2) retains two predictors (mean condition of juniper, negative; total percentage tree cover, positive) and two interactions (grazing:mean condition and grazing:tree cover). Grazing affects both mean juniper condition and tree cover, lowering francolin presence in areas of high 
TABLE 1 Distance analysis of francolin density (with 95\% confidence intervals, CI), and cluster density and size, using a half-normal model with a cosine function.

\begin{tabular}{lclcc}
\hline & Estimate $(95 \% \mathrm{CI})$ & $\mathrm{df}$ & $\mathrm{SE}$ & \% coefficient of variation \\
\hline Probability of detection per location & $0.26(022-0.32)$ & 45 & 0.027 & 10.18 \\
Effective strip width $(\mathrm{m})$ & $39.58(32.27-48.56)$ & 45 & 4.03 & 10.18 \\
Density of birds $\left(\mathrm{km}^{-2}\right)$ & $59.57(37.90-93.61)$ & 64.92 & 13.66 & 22.93 \\
Density of bird clusters $\left(\mathrm{km}^{-2}\right)$ & $28.90(18.90-44.20)$ & 50.40 & 6.18 & 21.39 \\
Mean cluster size & $1.74(1.41-2.16)$ & 46 & 0.18 & 32.56 \\
Expected cluster size & $2.06(1.75-2.43)$ & 45 & 0.17 & 8.26 \\
\hline
\end{tabular}

grazing and increasing francolin presence in areas of low grazing (Fig. 3). The effect of grazing is mediated through juniper condition and tree cover; grazing is not a significant main effect on its own. The effect of grazing is significantly higher where mean juniper condition is low and in areas of high tree cover. Grazing tends to halve the probability of francolin presence from a mean of 0.26 in ungrazed areas of high tree cover and low juniper condition to 0.13 in similar but grazed areas.

\section{The nature of human influence in the Forêt du Day}

The interviews revealed that goats, sheep and donkeys tend to graze locally in and around villages in open $A$. seyal woodland but cows require higher quality herbs found only in the forest. The effects of non-cattle livestock on the forest are therefore probably insignificant in comparison to cows and are not considered further here. The total number of cows grazing in the forest was estimated to be 1,156-2,411, all of which graze in either the Garab (70\%) or the Barabarre (30\%) regions (depending on village location). This is supported by our field observations.

A general log-linear model showed that there is a strong significant interaction between frequency of francolin sighting and region (analysis of deviance $\chi^{2}, \mathrm{df}=6, \mathrm{P}<0.001$ ). Villagers sighted francolins most frequently in the Garab and Adonta regions. The interview responses thus correspond spatially with the empirical findings from the transect surveys.

Eighty percent of interviewees thought that abundance of the francolin had declined. There was no significant difference in responses between villages $\left(\chi^{2}=4.63, \mathrm{df}=4\right.$,

TABLE 2 Minimum adequate model for francolin presence/ absence (see text for further details). Model deviance is 182.o.

\begin{tabular}{lc}
\hline Parameter & Value \\
\hline Intercept & $-2.90^{\star * *}$ \\
Mean condition & $-2.53^{\star *}$ \\
Tree cover & $0.199^{\star * *}$ \\
Mean condition:grazing & $0.769^{\star *}$ \\
Tree cover:grazing & $-0.0522^{\star * *}$ \\
\hline
\end{tabular}

${ }^{* * *} \mathrm{P}<0.001 ;{ }^{* *} \mathrm{P}<0.01 ; \mathrm{df}=229$
$\mathrm{P}>0.05$ ), suggesting that all villagers in the area have perceived the decline. The villagers tended to agree that the decline started around the time of commencement of juniper forest death, c. 1990. This corresponds with previous research (Welch \& Welch, 1998; Magin, 2001; Bealey et al., 2006). Seventy-six percent of villagers thought that the francolin is important, mainly because of its possible nutritive value but also simply for its existence as part of the forest. Few had heard of people who now eat or hunt it but a few older interviewees mentioned that in former times, when the francolin was so abundant that it approached village boundaries, they trapped them for food. The rarity of the francolin today means that even opportunistic catching of birds is difficult.

The majority of interviewees $(57 \%)$ blamed the death of the forest on drought, $17 \%$ of people were not sure why the forest was dying, and only $4 \%$ blamed overgrazing. A combination of planting new juniper trees and creating new exclosures was the most popular management idea to aid the conservation of the forest (29\% of responses), almost $25 \%$ of people said nothing could be done to save the forest, $15 \%$ were unsure what could be done, $23 \%$ were in favour of exclosures and $8 \%$ in favour of planting new junipers.

\section{Discussion}

\section{The francolin population}

It appears that the Forêt du Day is the bird's stronghold as it is the only area in the region with a large area of continuous suitable habitat. The estimate of 38-94 individuals $\mathrm{km}^{-2}$ is an average value for the study area and local population densities will vary depending on habitat suitability.

Three factors could potentially have resulted in an overestimate of the francolin population: (1) It was not always possible to distinguish between adults and juveniles and thus some clusters were potentially family groups. The density estimate should therefore be considered to represent the entire population, not just adults, and we may have therefore overestimated population size by not accounting for potentially poor juvenile survival (Mentis \& Bigalke, 


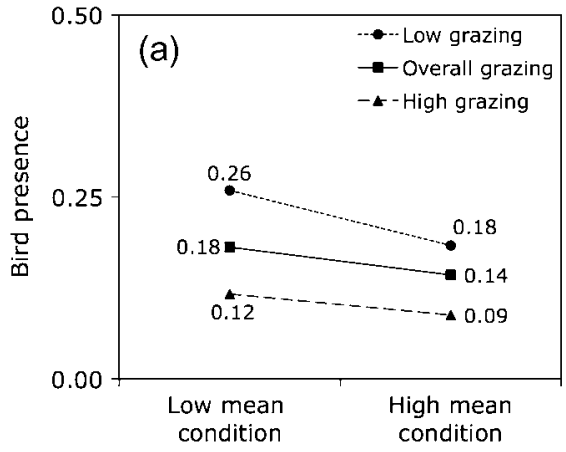

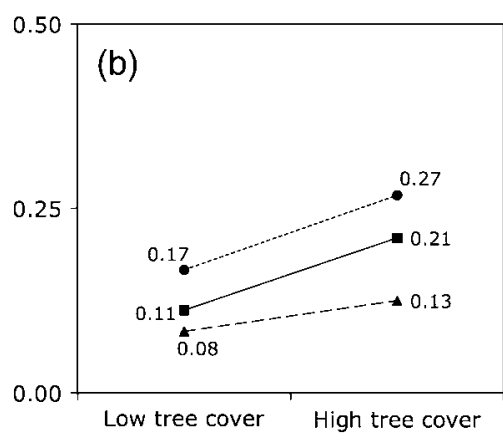

Fig. 3 Illustration of (a) mean juniper condition:grazing and (b) tree cover:grazing interactions in relation to francolin presence. Low and high mean condition and tree cover are calculated by dividing the data set in half, with the lowest $50 \%$ of values in one data set and highest values in the other. Values shown are averages.
1980). (2) Detection of a cluster may have affected detection of others nearby if the detected individual(s) noticed the observer and caused disturbance, and the Distance model does not take into account bird behaviour, such as territoriality (Buckland et al., 2001). With transects in close proximity, we cannot rule out the possibility that we counted birds more than once and thus overestimated population size. (3) Different habitats and topographies (e.g. wadis and open woodland) will have different detection probabilities, reducing the accuracy of our population estimate. Taking these potential limitations into account, we suggest that the total francolin population in the Forêt du Day may be in the lower half of the confidence interval, i.e. $285-450$ individuals.

\section{Predictors of francolin presence}

The Djibouti francolin has previously been assumed to be strongly associated with juniper forest (McGowan, 1995). However, the minimum adequate model for bird presence indicates that francolin presence is higher in areas of low juniper condition but high total tree cover. Francolins seem to prefer high tree cover irrespective of whether it includes juniper. The presence of closed-canopy forest, therefore, may be more important for francolins than juniper health. Similarly, the blood pheasant Ithaginis cruentus in China (Chen-xi et al., 2000) is often found in areas of secondary forest, where deciduous trees have replaced the original coniferous forests. Like the Djibouti francolin, the handsome francolin Francolinus nobilis in western Uganda prefers dense patches of forest over open areas (Fuller \& Ssemmanda, 2005). All these species may be finding suitable habitat in degraded areas. The death of junipers could be a cause of francolin decline but we have no unequivocal evidence that directly supports this.

Box is the most common tree in the forest and comprises the majority of total tree cover. Box percentage cover is significantly and negatively associated with juniper condition (Pearson's $r=-0.34, \mathrm{df}=272, \mathrm{P}<0.001$ ). Following the death of the juniper forest it appears that box has replaced juniper in some areas. The TWINSPAN results show that c. $49 \%$ of the forest area is dominated by box, which is present as an indicator in four of the eight plant communities, and $70 \%$ of the francolin observations were in these box-dominated areas. Box is a much faster growing tree than juniper and it seems likely that a substantial change in plant community composition has taken place following the decline of juniper.

Interpretation of the minimum adequate model shows that in areas with high tree cover and few living juniper (i.e. low mean juniper condition), compared to areas with low tree cover and denser living juniper (i.e. high mean juniper condition), francolin presence is higher in areas of low grazing than in areas of high grazing (Fig. 3). Why should grazing alter francolin presence in these areas of high tree cover more so than in more open woodland with healthier juniper? One possibility is that in open woodland (low tree cover), forage for francolins may be of a better quality as more herbs are present, and grazing has a smaller effect on their abundance because forage and shelter are sufficient for both livestock and francolins. In areas with denser trees, competition between animals and francolins for forage may be greater as understorey herbs are less abundant. Nevertheless, the fact that francolins appear to be favouring areas with high tree cover, and that in these areas the effect of grazing is more pronounced, is a cause for concern because grazing intensity is generally high in the whole region. As livestock continue to roam further and exploit new areas (especially in times of drought) these important high-quality habitats for francolins will become increasingly threatened.

An alternative hypothesis is that because grazing is significantly negatively correlated with tree cover (Pearson's $r=-0.33, \mathrm{df}=328, \mathrm{P}<0.001)$ francolins may be escaping from livestock to areas that have a denser forest canopy, where disturbance by livestock is less and quality of forage may be higher. The effects of grazing in these sheltered areas are high because when livestock are present bird presence is significantly lower. Francolins may also move to higher, more shaded, areas later in the summer that are less affected by drought.

Evidence of possible edge effects is apparent. Francolins were more abundant in the east, in the heart of the forest habitat, than in the west. Their absence from the western edge of the forest is not surprising given that this is closest 
to the villages, with many clearings. Edge effects for other ground-dwelling birds have been documented in montane forests, e.g. in the case of the chestnut-bellied hill-partridge Arborophila javanica (Nijman, 2003), which prefers the forest interior to edges.

The performance of the general linear model is limited by the accuracy of the data. The presence-absence method accounts for individuals that are present and detected but not for those that are present and undetected. Therefore, the probability of occurrence in certain areas (especially those with low visibility) could have been underestimated. Even though the random effect of transect number did not explain any variation, the placement of transects across the study area could do so. Not all transects could be systematically placed as some areas were too far from the camp to allow transects to be walked within the same daily time interval. Topography also limited the ability to conduct transects. For example, some transects had to be positioned in wadis or along ridges, and different vantage points have different detection distances. However, it is difficult to eliminate bias completely as detection distances will always vary in such a diverse and patchy mountainous habitat. We did not stratify our analysis by topography or habitat type as this would have reduced the observations in each stratum to numbers that were too small to provide meaningful results. Finally, although bird observations (visual and audible) were truncated $150 \mathrm{~m}$ either side of the transect, there may have been occasions when a bird beyond the 150-m mark was inadvertently included.

This study has not taken into account whether francolins move between areas at different times of the day, month or season, and this limits what we can infer from the model. Residual deviance is present and there are likely to be unmeasured factors causing this, such as human and predator disturbance and presence of key food plant species (such as the fruit of Datura metel). Detailed observational studies would help elucidate such variables. Nonetheless, we noted that birds were generally present in the same areas throughout the day. Bird locations were predictable when walking around the area, and were often encountered in the same location on multiple occasions.

We recommend that any future population estimates or monitoring of the Djibouti francolin uses more transects, in closer proximity to one another, to sample a larger proportion of the area. Transects should also be repeated at different times of the day and seasons to determine any daily or seasonal changes in density. Future research could also incorporate long-term radio tracking to examine francolin habitat preferences.

\section{Putting the results in a social context}

The interviews with villagers confirmed the empirical data and thus provide support for the accuracy of the field methods. The fact that most people thought drought was the main reason for the death of juniper shows that they have some understanding of a possible reason for the decline of the forest. Similarly, almost everyone who thought that the francolin population had declined attributed this to drought. Given the importance of grazing in determining francolin presence, any conservation action plan will need to tackle overgrazing. But with only $4 \%$ of villagers blaming grazing, this could be problematic. Any community-based conservation programme will need to address the concerns of the villagers with respect to the importance of grazing their livestock and will need to draw their attention to the possible effects of livestock on the forest.

This could be achieved by demonstrating the effect of exclosures on forest and plant regeneration. Two 3-year-old experimental exclosures exist in the forest and they clearly demonstrate the effect of grazing: juniper regeneration within the exclosures is high and there is thick herb and grass cover throughout. The exclosures are popular with villagers as solutions to the juniper forest decline but this contradicts the fact that only $4 \%$ blamed grazing for juniper decline. The villagers may be protecting their interests, as grazing their livestock everyday is an important livelihood requirement. A further $37 \%$ mentioned that planting new juniper trees would be beneficial but many raised the issue of water shortages and the difficulty of helping the forest without adequate natural water sources. Even though villagers receive sufficient piped water from wells via pumps, they did not seem to favour using this resource for watering trees, probably because of its limited availability.

The ideas for forest management provided by villagers are reassuring for community-based conservation. People were concerned about the francolin and the forest; in their minds the two issues were linked. However, $25 \%$ of interviewees claimed that nothing could be done to save the forest. This attitude will need to be addressed as local momentum is an integral component of successful communitybased conservation.

It is crucial that future conservation programmes incorporate the needs of the villagers, including livestock security, to obtain their expertise and manpower for management of the forest and implementation of any conservation actions. Any conservation plans will thus need to be ecosystem oriented, including the people in the ecosystem, rather than francolin oriented. As the factors that correlate with francolin abundance are unlikely to be identical to those affecting juniper health, such an ecosystem approach will need to be accompanied by specific protection for both the francolin and the juniper.

Funding has now been secured for maintaining and, where possible, expanding the current juniper exclosures, and for a juniper nursery in Day village. The latter will not only propagate junipers but will also involve the villagers in 
the conservation of the ecosystem. As our results indicate that francolins are associated with high tree cover but not necessarily high juniper cover, we recommend limitation of grazing in areas of high altitude where the juniper forest is regenerating and on those parts of the Garab plateau where francolins are more abundant.

\section{Acknowledgements}

We would like to thank our field guides Mohammed Abdullah and Yayo Ali, Lt Col. Mohamed Djama Doualeh and the Republican Guard for permission to undertake research in the Forêt du Day, and Dr Shahina Ghazanfar and the Royal Botanic Gardens, Kew, UK, for help with identification of Djibouti flora.

\section{References}

Ahmed, M., Nagi, E.E. \& Wang, E.L.M. (1990) Present state of juniper in Rodhmallazi Forest of Baluchistan, Pakistan. Pakistan Journal of Forestry, 12, 227-236.

Asmodé, J.-F. (1989) Status and Trends of the Juniper Woodland in the Taif Area. Proceedings of Workshop I on the Ecological Imperatives for Sustainable Development in the Kingdom of Saudi Arabia. National Commission for Wildlife Conservation and Development, Riyadh, Saudi Arabia.

Atкins, R.A. \& TentiJ, M. (1999) The orange-necked partridge and five other galliformes in two protected areas in southern Vietnam. Annual Review of the World Pheasant Association 1998/1999, 49-52.

B A tes, D. (2007) lme4: Linear Mixed-Effects Models Using S4 Classes. R Package Version 0.99875-6. The R-Project for Statistical Computing. Http://www.r-project.org/ [accessed 3 August 2009].

Bealey, C.E., McGowan, P. \& Rayaleh, H.A. (2006) Djibouti Francolin Conservation Project: Second Phase 2006. World Pheasant Association, Fordingbridge, UK.

BirdLife (2008) Data Zone. Http://www.birdlife.org [accessed 3 February 2009].

BLOT, J. (1985) Contribution to our knowledge of the biology and ecology of the pale-bellied francolin Francolinus ochropectus Dorst and Jouanin. Alauda, 63, 244-256.

B LOT, J. (1986) Typologie de la vegetation de la République de Djibouti. ISERST, Higher Institute for Scientific and Technical Studies and Research, Djibouti.

B LOT, J. (1994) Les écosystèmes forestiers tropicaux de montagne: l'exemple des forêts à Juniperus procera (République de Djibouti). In Evolution de L'environnement en Zone tropicale: Enregistreurs et Indicateurs (eds R. Maire, S. Pomel \& J.N. Salomon), pp 385-411. Bordeaux University Press, Bordeaux, France.

Blot, J. \& Hajar, A.S. (1994) Evaluation of the Ecological Situation of the Raydah Protected Area. First Report. National Commission for Wildlife Conservation and Development, Riyadh, Saudi Arabia.

Borghesio, L., Giannetti, F., Ndang'ang'a, K. \& Shimelis, A. (2004) The present conservation status of Juniperus forests in the south Ethiopian Endemic Bird Area. African Journal of Ecology, 42, 137-143.

Buckland, S.T., Anderson, D.R., Burnham, K.P., Laake, J.L., Borchers, D.L. \& Thomas, L. (2001) Introduction to Distance Sampling. Oxford University Press, Oxford, UK.
Chen-Xi, J., Yue-huA, S. \& Yun, F. (2000) Occurrence of blood pheasant Ithaginis cruentus in relation to habitat fragmentation in southern Gansu, China. In Galliformes 20oo: The 2nd International Galliformes Symposium (eds M. Woodburn, P. McGowan, J. Carroll, A. Musavi \& Z. Zheng-Wang), pp. 86-90. Royal Chitwan National Park and World Pheasant Association, Kathmandu, Nepal.

Crawley, M. (2007) The R Book. Wiley, Chichester, UK.

Crowe, T.M., Keith, S. \& Brown, L.H. (1986) Galliformes. In The Birds of Africa, Vol. 2 (eds E.K. Urban, C.H. Fry \& S. Keith), pp. 1-75. Academic Press, London, UK.

Dai, B., Dowell, S.D., Martins, R.P. \& Williams, R.S.R. (1998) Conservation status of the Sichuan hill-partridge Arborophila rufipectus in China. Bird Conservation International, $8,349-359$.

del Hoyo, J., Elliott, A. \& Sargatal, J. (1994) Handbook of the Birds of the World. Volume 2. New World Vultures to Guineafowl. Lynx Edicions, Barcelona, Spain.

DranzoA, C. (1998) A survey of Nahan's francolin in three tropical rainforests of Uganda. WPA News, 57, 28-52.

Emerton, L. (1999) Djibouti Biodiversity: Economic Assessment. IUCN, Nairobi, Kenya.

Fisher, M. (1997) Decline in the juniper woodlands of Raydah reserve in southwestern Saudi Arabia: a response to climate changes? Global Ecology and Biogeography Letters, 6, 379-386.

Fuller, R.A., Carroll, J.P. \& McGowan, P.J.K. (2000) Status Survey and Conservation Action Plan 2000-2004: Partridges, Quails, Francolins, Snowcocks, Guineafowl, and Turkeys. IUCN, Cambridge, UK.

Fuller, R.A. \& Ssemmanda, R. (2005) Assessing the status of the handsome francolin Francolinus nobilis in Bwindi Impenetrable National Park, western Uganda. Scopus, 25, 41-50.

Gardner, A.S. \& Fisher, M. (1994) How the forest lost its trees: just so stories about juniper in Arabia. Journal of Arid Environments, 26, 199-201.

Gouvernement de Dibouti (2000) Monographie Nationale de la Diversité Biologique de Djibouti. Direction de l'Environment, Ministère de l'Habitat, de l'Urbanisme, de l'Environment et de L'Aménagement du Territoire, Djibouti.

Hill, M.O. \& Smilauer, P. (2005) TWINSPAN for Windows Version 2.3. Centre for Ecology and Hydrology, Huntingdon, UK, and Ceske Budejovice, Czech Republic.

IUCN (2008) 2008 IUCN Red List of Threatened Species. IUCN, Gland, Switzerland. Http://www.iucnredlist.org [accessed 13 February 2009].

Javed, S., Qureishi, Q. \& Rahmani, A.R. (1999) Conservation, status, and distribution of swamp francolin in India. Journal of the Bombay Natural History Society, 96, 16-23.

Keane, A., Brooke, M.L. \& McGowan, P.J.K. (2005) Correlates of extinction risk and hunting pressure in gamebirds (Galliformes). Biological Conservation, 126, 216-233.

Keller, L.F. \& Waller, D.M. (2002) Inbreeding effects in wild populations. Trends in Ecology \& Evolution, 17, 230-241.

Laurance, W.F., Ferreira, L.V., RankinDeMerona, J.M. \& LAURANCE, S.G. (1998) Rain forest fragmentation and the dynamics of Amazonian tree communities. Ecology, 79, 2032-2040.

Laurance, W.F. \& Williamson, G.B. (2001) Positive feedbacks among forest fragmentation, drought, and climate change in the Amazon. Conservation Biology, 15, 1529-1535.

Lawes, M.J., Fly, E. \& Piper, S.E. (2006) Gamebird vulnerability to forest fragmentation: patch occupancy of the crested guineafowl (Guttera edouardi) in Afromontane forests. Animal Conservation, 9, 67-74. 
MAgIN, G. (2001) Djibouti. In Important Bird Areas in Africa and Associated Islands: Priority Sites for Conservation. BirdLife Conservation Series No. 11 (eds L.D.C. Fishpool \& M.I. Evans), pp. 233-239. BirdLife International, Newbury and Cambridge, UK.

McGowan, P.J.K., Dowell, S.D., Carroll, J.P. \& Aebischer, N.J. (1995) Partridges, Quails, Francolins, Snowcocks and Guineafowl: Status Survey and Conservation Action Plan, 1995-1999. IUCN, Gland, Switzerland.

Mentis, M.T. \& Bigalke, R.C. (1980) Breeding, social behaviour and management of greywing and redwing francolins. South African Journal of Wildife Research, 10, 133-139.

Miskell, J. (2000) An Ecological and Resource Utilisation Assessment of Gacaan Libaax, Somaliland. IUCN Eastern African Programme, Somali Natural Resources Management Programme. IUCN, Cambridge, UK.

Nijman, V. (2003) Distribution, habitat use and conservation of the endemic chestnut-bellied hill-partridge (Arborophila javanica) in fragmented forests of Java, Indonesia. Emu, 103, 133-140.

Owens, I. \& Bennett, P. (2000) Ecological basis of extinction risk in birds: habitat loss versus human persecution and introduced predators. Proceedings of the National Academy of Sciences, 97, 12144-12148.

Sekercioglu, C.H. (2007) Conservation ecology: area trumps mobility in fragment bird extinctions. Current Biology, 17, R283-R286.

Sekercioglu, C.H., Daily, G.C. \& Ehrlich, P.R. (2004) Ecosystem consequences of bird declines. Proceedings of the National Academy of Sciences, 101, 18042-18047.

Stephens, S.E., Koons, D.N., Rotella, J.J. \& Wiley, D.W. (2004) Effects of habitat fragmentation on avian nesting success: a review of the evidence at multiple spatial scales. Biological Conservation, 115, 101-110.

Thomas, L., Laake, J.L., Strindberg, S., Marques, F.F.C., Buckland, S.T., Borchers, D.L. et al. (2006) Distance 5.o. Release 2. Research Unit for Wildlife Population Assessment, University of St. Andrews, UK.
USAID (United States Agency for International Development) (2008) Djibouti Center, Famine Early Warning Systems Network. Http://www.fews.net/pages/country.aspx?gb=dj\&l=en [accessed 30 May 2008].

WelCh, G. \& WelCh, H. (1985) Observations on the endemic Djibouti francolin (Francolinus ochropectus) with emphasis on potential threats to the population. World Pheasant Association Journal, 10, 65-71.

WELCH, H.J. \& WELCH, G.R. (1998) A Report on the Birds of Djibouti and the Bankouale Palm Livistona carinensis. IUCN, Djibouti.

White, F. (1983) The Vegetation of Africa: A Descriptive Memoir to Accompany the UNESCO/AETFAT/UNSO Vegetation Map of Africa. UNESCO, Paris, France.

\section{Biographical sketches}

Zomo S.Y. Fisher specializes in the effects of climate change on biodiversity and is currently working as a climate change consultant. SAMANTHA CARTWRIGHT is undertaking doctoral research in avian ecology, focusing on the individual life-history effects of natal environment on Mauritius kestrels. CLIVE BEALEY has been working on the conservation of the Djibouti francolin and Forêt du Day since 2003. He is currently also working for the UK government as a monitoring specialist. Houssein A. Rayaleh is Director of the NGO Djibouti Nature, which preserves wildlife in Djibouti, and is a BirdLife Species Guardian. Philip McGowan is director of the World Pheasant Association. He is concerned with ensuring that no species of Galliformes goes extinct, and balancing the needs of all 300 Galliformes species with the human communities that live alongside them. E.J. MilneR-Gulland's research lies at the interface of human and ecological systems, with a particular focus on the conservation of harvested species. Her group's website is www. iccs.org.uk. 